\title{
8
}

\section{im

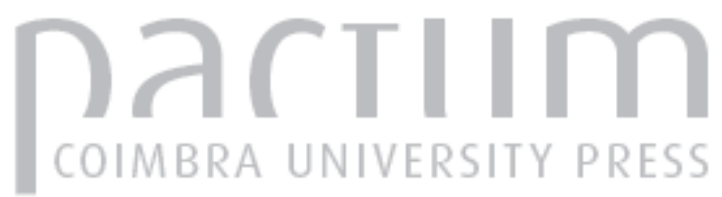

[Recensão a] Burke, Peter (2008) O que é História Cultural? Tradução Sérgio Goes de Paula

\author{
Autor(es): $\quad$ Carvalho, Andréa Silva
}

Publicado por: Imprensa da Universidade de Coimbra

URL persistente:

URI:http://hdl.handle.net/10316.2/38664

DOI:

DOI:http://dx.doi.org/10.14195/1645-2259_15_20

Accessed : $\quad$ 26-Apr-2023 16:26:00

A navegação consulta e descarregamento dos títulos inseridos nas Bibliotecas Digitais UC Digitalis, UC Pombalina e UC Impactum, pressupõem a aceitação plena e sem reservas dos Termos e Condições de Uso destas Bibliotecas Digitais, disponíveis em https://digitalis.uc.pt/pt-pt/termos.

Conforme exposto nos referidos Termos e Condições de Uso, o descarregamento de títulos de acesso restrito requer uma licença válida de autorização devendo o utilizador aceder ao(s) documento(s) a partir de um endereço de IP da instituição detentora da supramencionada licença.

Ao utilizador é apenas permitido o descarregamento para uso pessoal, pelo que o emprego do(s) título(s) descarregado(s) para outro fim, designadamente comercial, carece de autorização do respetivo autor ou editor da obra.

Na medida em que todas as obras da UC Digitalis se encontram protegidas pelo Código do Direito de Autor e Direitos Conexos e demais legislação aplicável, toda a cópia, parcial ou total, deste documento, nos casos em que é legalmente admitida, deverá conter ou fazer-se acompanhar por este aviso.

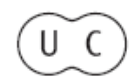




\section{Revista \\ de História \\ da Sociedade \\ e da \\ Cultura}

Século de Ouro

Siglo de Oro 


\section{Burke, Peter (2008) O que é História Cultural? Tradução Sér- gio Goes de Paula, $2^{\text {a }}$ edição revista e ampliada. Rio de Janeiro: Zahar, 177 pp., ISBN: 978-85-378-0869-6}

A obra assume uma perspectiva sobre a discussão teórica da História Cultural dos anos setenta do século XX na Europa e reflete, sobretudo, as diferenças e os conflitos culturais na produção do conhecimento histórico. A definição de cultura revela que qualquer explicação de História Cultural caminha para o campo interdisciplinar, local e global. Como bem sublinha Peter Burke, um dos aspectos que melhor caracteriza a prática da História Cultural nas décadas de sessenta a noventa do século XX é o caminho de aproximação da História à Antropologia, essencialmente por conta dos problemas da compreensão do termo cultura.

O primeiro capítulo - A grande tradição - remete para a tradição alemã. Recupera a noção de "espírito da época" e insiste na exploração das formas, linguagens e sentimentos de expressão cultural. Analisa os contributos dos sociológos Max Weber e Norbert Elias que, nos finais dos anos trinta, estudaram o processo civilizador. Aborda a noção de cultura na obra de Aby Warburg, que elegeu como campo de reflexão o Renascimento e de Ernst Gombrich que, nos anos sessenta, estudou a relação entre verdade e estereótipos.

A década de trinta, em função da ascensão de Hitler ao poder, foi marcada pela fuga de cientistas para Londres e Estados Unidos e por um recurso mais insistente no conceito de "civilização". A palavra-chave era "civilização", mais que "cultura" (p. 19).

A diáspora dos intelectuais alemães possibilitou o desenvolvimento de diferentes enfoques sobre cultura e sociedade. Na década de cinquenta, o marxista Arnold Hauser estudou a história social da arte. Na década de sessenta, a História Social fez a descoberta do povo e, na década seguinte, a "formação da classe operária inglesa" de Edward Thompson assinalou o lugar central doravante conquistado pela cultura popular. Na linha de valorização da História Social da Cultura merecem análise cuidadosa os contributos de Jacques le Goff e dos historiadores ligados à Escola dos Annales.

No segundo capítulo - Problemas da História Cultural -, Peter Burke reflete que os métodos, as fontes e as conclusões têm confiabilidade relativa, por serem produzidos e escolhidos com elevado condicionamento. "O problema levantado por Clapham acerca das leituras subjetivas dos textos é bem mais difícil de resolver" (p. 26). 
O terceiro capítulo - A vez da Antropologia Histórica - refere a aproximação da Antropologia com a História, ressaltando a importância dos valores culturais para explicar a produção e o consumo. Os historiadores J. Elliott e R. Chartier voltaram a sua atenção para o pensamento, as ideias e a produção escrita. $\mathrm{O}$ antropólogo Geertz ampliou o termo cultura e influenciou historiadores, como Robert Darnton. E nesta lista de historiadores da História Cultural do final do século XX incluem-se: Georges Duby, Le Roy Ladurie, Daniel Roche, Lynn Hunt e, entre outros, Carlo Ginzburg.

Na década de setenta do século $\mathrm{XX}$, cresceu a discussão entre macro-história e micro-história. A micro como reação às explicações das narrativas e generalizações dos processos da civilização ocidental e como reação à globalização em favor da cultura regional e local.

O capítulo 4 questiona a emergência de um novo paradigma de pesquisa. O novo modo de fazer História da Cultura é ponto de partida de uma outra teoria cultural. Esta teoria cultural tem reforço de importantes teóricos, tais como, Michel Foucault, Nobert Elias, Jürgen Habermas, Mikhail Bakhtin e Pierre Bourdieu. Observamos as variedades da Nova História Cultural de Mikhail Bakhtin com os conceitos de carnavalização e subversão da alta cultura pela baixa e a prevalência dada a muitas vozes, como se de um texto de polifonia se tratasse. É de Norbert Elias o conceito de processo civilizador. Apesar de criticado, tem sido aplicado em múltiplas pesquisas de historiadores. Por seu turno, Michel Foucault com os conceitos de contrários, progresso e evolução analisou as descontinuidades culturais, as rupturas e a ideia de invenção da cultura, de redes de ideias e pensamentos ao nível da microfísica do poder. "Se Elias enfatiza o autocontrole, Foucault chamava a atenção para o controle sobre o eu, especialmente o controle sobre os corpos exercidos pelas autoridades" (p. 58).

Por fim, saliente-se Pierre Bourdieu com a ideia de "reprodução cultural" teoria da prática, de habitus que distingue de regras, emprego de bens, produção e capital relacionado com a cultura e a teoria da estratégia de distinção cultural a afirmação da identidade social.

Novos paradigmas da Nova História Cultural dos quais se destacam: 1 - O estudo das práticas, a exemplo das práticas religiosas diferentes da teologia; da fala diferente da linguística; do experimento diferente da teoria e assim profissionalizaram-se vários temas, tais como, esportes, maneiras à mesa, consumo, fala, viagem, leitura etc.. 2 - Estudos das representações, construção do imaginário social, reflexo das estruturas sociais e criação das ideias. 3 - A História da memória e da ação e aceleração das transformações sociais que ameaçam a identidade, apesar de sabermos que as memórias são 
"contaminadas" pela cultura, por grupos diferentes, por momentos diferentes. 4 - O estudo da cultura material - os estudos dos objetos para compreensão de mudanças e relações sócio-culturais. 5 - O outro paradigma da Nova História Cultural é a história do corpo centrada na identificação dos elementos culturais da vida, nos aspectos físicos e na carga simbólica dos gestos, higiene, etc..

A revolução da História Cultural evoluiu a partir da Antropologia histórica, neste sentido, o autor refere os contributos de Jaques Le Goff, Natalie Zemon Davis, e Keith Thomas.

O quinto capítulo - Da Representação à Construção - desenvolve uma análise da mudança da História Cultural para a História Social da Cultura e para a produção da realidade criada, em que a linguagem não é mais o reflexo do objeto e as histórias apresentam versões quanto ao ponto de vista escolhido: vista de baixo, a visão dos colonizados, a visão dos derrotados, das classes subalternas, das mulheres etc.. É a criação da realidade e o declínio do determinismo.

Quanto às variáveis desse construtivismo podemos perceber a reutilização do pensamento de Michel de Certeau que analisou as práticas das pessoas comuns, a criatividade e a inventividade nas apropriações e no consumo das ideias e objetos.

A construção do conceito de género, masculino e feminino, e as distinções de masculinidade e feminilidade são modificadas historicamente. Refira-se ainda outro valor do construtivismo: a construção das comunidades, sob o signo do livro. "Comunidades Imaginadas" (Benedict Anderson) e "invenção da tradição" (Hobsbawm) em que se mesclam múltiplas tradições, antigas, recentes e (re)inventadas. Em relação à construção da monarquia, como em relação à construção da nacionalidade são usadas as festividades, coroações, casamentos, funerais, procissões religiosas e paradas militares para evidenciar a construção de um ideal de unidade (p.88).

Em relação à construção de identidades individuais, importa realçar que estas representam um eu forjado no coletivo, que está para além da biografia como construção de identidade para si mesma. É a chamada virada performativa e modelo dramatúrgico. Dizer a performance de consensos, das festividades, performance de nacionalismo, da história ou da memória, performance da linguagem, da metáfora que não só expressa, porém ajuda a criar a identidade, ainda a performance como o contrário de regras culturais, dos improvisos de recriação e de conflito dos significados. Igualmente a ascensão do ocasionalismo - ideia de distanciamento das regras fixas, respostas flexí- 
veis às lógicas sociais, a exemplo do tipo de linguagem ou gesto para cada tema, cargo ou ocasião.

$\mathrm{O}$ autor trabalha ainda com o conceito de desconstrução, categoria que em cada tempo os historiadores utilizam como projeção de valores sobre o do passado. Portanto, o construtivismo é antagónico, a visão simplista da identidade, ainda cria problemas cuja solução está longe de ter respostas para questões como: que restrições se constroem? A partir de quê? Ou melhor, há uma criação contínua da cultura a partir de elementos velhos e novos?

O sexto capítulo - Além da virada cultural? - Assinala o retorno a Burckhardt e sustenta que a história cultural tradicional persiste nos estudos da alta cultura, coexistindo com o interesse despertado pela cultura popular. Os deslocamentos e ênfases da Nova História Cultural acontecem a exemplo de O queijo e os vermes de Carlo Ginzburg.

Outras extensões da Nova História Cultural são os estudos da História Cultural da política, da violência e das emoções. A cultura e a política estão presentes em muitas produções sobre os simbolismos das monarquias e repúblicas. É a chamada cultura política de Lynn Hunt que trata da Revolução Francesa e seus comportamentos políticos, além de Thompson, Levi Strauss, Foucault e Derrida que também se dedicaram ao tema. Temos, também, Shahid Amim sobre a imagem de Gandi na consciência camponesa. $\mathrm{O}$ movimento de formação dos grupos de estudos dos subalternos na Índia, na Irlanda e na América Latina servem de exemplo da expansão da Nova História Cultural.

A reflexão de uma vingança da História Social como reação à expansão da Nova História Cultural sugere que esta foi muito longe e que existe um problema de subjetividade, de definição, de método e fragmentação, para além dos limites próprios do construtivismo. Percebe-se a existência de problemas na relação entre cultura e sociedade e não se pode perder de vista as estruturas políticas e económicas. Como a Nova História, a Nova História Cultural evoluiu. Novos objetos, novos problemas, novas abordagens, novas fontes, novos métodos são objecto de intenso debate.

Quanto ao tópico "as fronteiras e o encontros" existe uma tentativa de romper com a fragmentação, com o conceito de fronteira cultural e a questão é de onde se olha cada área cultural, ou seja, como fazer as distinções, como tratar os grupos fluidos entre estas fronteiras e as zonas de contacto e convivência de opostos numa cultura híbrida.

A narrativa na História Cultural foi anteriomente ligada à visão tradicional, a narrativa volta para dar voz às pessoas comuns, histórias de vida, narrativas culturais suas estruturas e versões, na perspectiva do leitor. O desafio 
é fazer isso sem dar à História um enredo triunfalista e enfatizar a crítica e o conflito de visões e de sentido de cada narrativa.

Peter Burke observa que a Nova História Cultural pode chegar ao fim, todavia o seu percurso ainda está em crescimento, ou melhor, em processo. As questões persistem sem soluções e novas surgirão. Os historiadores culturais e sociais ampliam os seus territórios. Não existe defesa de que a História Cultural é a melhor forma de História, porém as suas contribuições são pertinentes e necessárias. E quaisquer que sejam os resultados não será possível retornar à compreensão positivista dos documentos históricos, uma compreensão literal onde não se destacam os simbolismos.

Concluímos que a História Cultural não é monopólio dos historiadores. É multidisciplinar, por esta razão torna-se difícil a sua definição. As invasões de fronteira e território são comuns entre a história literária, a arte e a antropologia, tomando emprestados os seus conceitos. Mas também com a sociologia, o folclore, a geografia, a arqueologia, a ecologia, entre outros. Para além disso, a História Cultural aproxima-se dos conceitos de performance social, construção cultural, tradição, herança, construção cultural dos espaços, antropologia cultural e arqueologia. Como projeção, até a ecologia se aproxima da História Cultural. O movimento dos estudos culturais, enfrentando embora a ameaça de ser engolido por outros contributos gerados a partir dele, cruza-se ainda com a história da memória e do quotidiano.

Enfim, algumas das questões levantadas nasceram do embate, da guerra, da cultura e da rejeição - a cultura dos homens brancos mortos, em contraponto com afro-americanos e do estudo das mulheres na história. E desta forma seguem o embate sobre o multiculturalismo, termo que pressupõe a existência de diversas culturas em um mesmo espaço, estimuladas a conservar as suas identidades. As questões levantadas suscitam a pergunta: onde estão as fronteiras culturais e o que é autencidade cultural? Os historiadores culturais não resolverão os problemas, porém têm a possibilidade refletir sobre tais questões. 